University of Nebraska - Lincoln

DigitalCommons@University of Nebraska - Lincoln

Sociology Department, Faculty Publications

Sociology, Department of

$12-2010$

\title{
The Effect of Early Maltreatment, Victimization, and Partner Violence on HIV Risk Behavior Among Homeless Young Adults
}

Lisa A. Melander

Kansas State University, Imeland@ksu.edu

Kimberly A. Tyler

University of Nebraska-Lincoln, kim@ktresearch.net

Follow this and additional works at: https://digitalcommons.unl.edu/sociologyfacpub

Part of the Sociology Commons

Melander, Lisa A. and Tyler, Kimberly A., "The Effect of Early Maltreatment, Victimization, and Partner Violence on HIV Risk Behavior Among Homeless Young Adults" (2010). Sociology Department, Faculty Publications. 129.

https://digitalcommons.unl.edu/sociologyfacpub/129

This Article is brought to you for free and open access by the Sociology, Department of at DigitalCommons@University of Nebraska - Lincoln. It has been accepted for inclusion in Sociology Department, Faculty Publications by an authorized administrator of DigitalCommons@University of Nebraska - Lincoln. 
Published in Journal of Adolescent Health 47:6 (December 2010), pp. 575-581; doi:10.1016/j.jadohealth.2010.04.010

Copyright $(02010$ Society for Adolescent Health and Medicine Published by Elsevier Inc. Used by permission.

Submitted December 10, 2009; accepted April 21, 2010; published online June 20, 2010.

\title{
The Effect of Early Maltreatment, Victimization, and Partner Violence on HIV Risk Behavior Among Homeless Young Adults
}

\author{
Lisa A. Melander \\ Department of Sociology, Anthropology, and Social Work, \\ Kansas State University, Manhattan, Kansas \\ Kimberly A. Tyler \\ Department of Sociology, \\ University of Nebraska-Lincoln, Lincoln, Nebraska \\ Corresponding author - Lisa A. Melander, Ph.D., Department of Sociology, Anthropology, and Social Work, \\ Kansas State University, 204 Waters Hall, Manhattan, KS 66506
}

\begin{abstract}
Purpose: The purpose of our study was to examine the relationship between child maltreatment, physical and sexual victimization, and partner violence victimization with human immunodeficiency virus (HIV) risk behaviors among a sample of homeless young adults from the midwestern United States.

Methods: Data are from the Homeless Young Adult Project. A total of 199 young adults aged 19-26 years were interviewed over 14 months using a systematic sampling strategy. The final sample included 172 young adults who were homeless or had a history of running away and being homeless.

Results: Results from the path analysis revealed that sexual abuse is directly linked with street sexual victimization which was positively associated with a greater number of HIV risk behaviors. Experiencing more types of physical abuse and neglect were positively correlated with partner violence victimization, which was, in turn, associated with more HIV risk behaviors. Those who suffered from more types of neglect also experienced more forms of sexual and physical victimization.

Conclusions: These findings have implications for service providers. Clinicians who serve homeless youth should recognize the potential effect that experiencing a variety of forms of victimization may have on health risk behaviors.

Keywords: homeless, young adults, abuse, victimization, partner violence, HIV risk behaviors
\end{abstract}

The acquisition of HIV (human immunodeficiency virus) is a serious health concern among adolescents and young adults. In the United States, an estimated number of 55,000-58,500 new HIV infections occur each year [1], and half of all new infections are believed to occur among those aged less than 25 years [2]. Common modes of HIV transmission include engaging in risky sexual and substance use behaviors such as inconsistent condom use, sexual contact with people at risk for HIV infection, and injection drug use [1,3]. Although HIV affects people in every socio-demographic group, certain individuals, such as homeless youth, may be at higher risk for contracting the virus and other sexually transmitted infections/diseases (STIs/STDs) as compared with the general adolescent population as a result of their participation in drug and sexual risk behaviors $[4,5]$. Furthermore, the prevalence of HIV in homeless youth has been found to be as high as $12 \%$ [6].
Although child maltreatment is an important correlate of HIV risk behavior (e.g., unprotected sex, intravenous [IV] drug use, and/or ever having an STD/STI) among homeless populations [7-9], it is presently unknown whether experiencing additional types of victimization further increases homeless youth's probability for engaging in HIV risk behaviors. Accordingly, the purpose of the present study was to examine the relationship between child maltreatment, physical and sexual victimization, partner violence, and HIV risk behaviors among homeless young adults. These findings may have implications for service provider intervention and prevention.

\section{Literature Review}

HIV risk among homeless youth

There are several reasons why homeless youth are at 
higher risk for contracting HIV compared with the general population. To meet their survival needs, some homeless youth trade sex for food, shelter, and other basic necessities [10-12]. Additionally, homeless youth commonly report having numerous sexual partners [11, 13] and high rates of STDs [11, 14-16], which are additional risk factors. Other unsafe sexual practices include low rates of condom use. Some studies show that less than one-half of homeless and runaway adolescents used a condom the last time they had sexual intercourse [14, 17]. A significant portion of homeless youth also participate in risky drug behaviors, including IV drug use and/or needle sharing [18-20], which further increases their risk for HIV infection.

Childhood physical and/or sexual abuse and street victimization are common experiences among the homeless $[21,22]$. Both maltreatment and victimization have been linked to HIV risk behaviors such as trading sex [12], unprotected sex [8], and IV drug use [7] among this population. Ennett et al. [23] also found that being sexually victimized was associated with HIV risk behaviors including survival sex, having more than 10 lifetime sex partners, and previously having an STD among homeless males and females. Additionally, the amount of time youth spend on the street has been directly linked to risky sexual behaviors [9] as well as indirectly associated with victimization among homeless youth [22].

\section{Partner violence and HIV risk}

Partner violence is another form of victimization that is associated with HIV risk behaviors among general population and other high risk samples [24-26]. Among urban minority teens, females who experienced more partner violence had increased inconsistent condom use compared with those who experienced less physical and/or emotional aggression, which places them at greater risk for HIV infection [27]. Partner violence victims may be at higher risk for contracting HIV because those who have infected partners may be forced to engage in unprotected sexual activities [28]. Additionally, partner violence may also limit a person's ability to negotiate safer sexual behaviors as victims may have decreased perceptions of control over sexual health [25-27] or may fear an abusive partner's response to a request for safe sex practices [29]. Some have also suggested that partner violence may establish a pattern of sexual risk taking [28].

To date, only a few studies have examined partner violence victimization among homeless and sheltered respondents [30]. Among a sample of 600 male and 300 female overnight and daytime shelter residents, North et al. [31] found that similar percentages of males and females reported hitting or throwing things at a partner $(12 \%$ and $17 \%$, respectively). Experiencing child abuse and neglect have also been associated with partner violence among homeless young adults [32]. Despite the limited research on partner violence among the homeless, these violent experiences could be an additional risk factor for HIV risk behaviors.

\section{Theoretical Orientation}

We draw on the risk-amplification model [33], which is a combination of life course theory and social interaction theory, as a framework for our study. According to this model, adolescents who experience child maltreatment (i.e., physical abuse, sexual abuse, and/or neglect) are at greater risk for running away as a means of escaping a negative environment. Street experiences and running away from home amplify negative developmental effects originating in the family, and these problems may increase homeless youths' risk for victimization on the street. In addition, youth may view relationship violence as normative and be more willing to accept or at least tolerate such behavior, because of their family histories of abuse. As such, they may be more likely to become involved with a violent partner. These victimization experiences, in turn, increase homeless youths' chances for participation in risky sexual and drug use behaviors (i.e., HIV risk behavior). On the basis of the aforementioned literature review and the risk amplification model, we examine the relationship between child maltreatment, physical and sexual victimization, partner violence, and HIV risk behaviors among homeless young adults. Specifically, we hypothesize that experiencing any form of child maltreatment will be positively associated with victimization, partner violence, and HIV risk behavior. We also expect sexual and physical victimization and partner violence to have direct, positive effects on HIV risk behaviors.

\section{Method}

Data are from the Homeless Young Adult Project, a pilot study designed to examine the effect of neglect and abuse histories on homeless young adults' mental health and high-risk behaviors. A total of 199 young adults were interviewed in three midwestern cities from April 2004 through June 2005. Of these, 144 were homeless and 55 were currently housed at the time of the interview. Homeless was defined as those currently residing in a shelter, on the street, or those living independently (e.g., with friends) because they had run away, had been pushed out, or had drifted out of their family of origin. The 55 young adults were chosen through peer nominations from their homeless counterparts. Despite being housed at the time of the interview, 28 of the 55 housed young adults had extensive histories of being homeless and had run away from home numerous times, and were thus retained for our analyses. The final sample used for this research included 172 young adults who were homeless or had a history of running away and being homeless.

Individuals who worked on past projects dealing with at-risk individuals, have served for several years in agencies and shelters that support homeless young people, and are very familiar with local street cultures were responsible for recruiting participants (through in-person contact and informational flyers) and conducting the interviews. Although the sex of the interviewer was 
not matched to that of the respondents, the interviewers were both male and female. Additionally, all interviewers completed the Collaborative Institutional Review Board Training Initiative course for the protection of human subjects in research. The sampling protocol, which was conducted repeatedly over the course of 14 months, included varying the times of the day on both weekdays and weekends that interviewers went to shelters and street locations where homeless people congregate. This systematic sampling strategy maximized locating homeless young adults and was used because it is well established that it is not possible to randomly sample homeless populations [34]. Interviewers informed respondents about the confidentiality of the study and that their participation was voluntary. They also obtained informed consent before the interview. The interviews, which were conducted in shelter interview rooms or quiet corners of fast food restaurants or coffee shops, lasted approximately 1 hour and all participants received \$25 for their involvement. Referrals for shelter, counseling services, and food services were offered to the young adults at the time of the interview. Although interviewers did not formally tally screening rates, they reported that very few young adults refused to participate. The Institutional Review Board at the University of Nebraska-Lincoln approved this study.

\section{Measures}

Gender was coded $0=$ male and $1=$ female. Age was a continuous variable that measured how old the respondents were at the time of the interview.

Number of times run was a single item indicator that measured the total number of times the young people had run away from home. This variable was collapsed because of skew, and the response categories included $1=$ ran away once, $3=$ ran away four or five times, and $6=$ ran away more than 20 times.

Sexual abuse was measured using seven items. For example, respondents were asked how often an adult or someone at least 5 years older had done the following to them before they were on their own and while they were under the age of 18: had you touch them sexually and put or tried to put anything or any part of their body into you sexually. Because of skew, the final variable was dichotomized $(0=$ no sexual abuse; $1=$ sexually abused at least once).

Physical abuse was measured using 16 items from the Conflict Tactics Scale-Parent Child (CTSPC) [35]. Respondents were asked how many times their caretaker had engaged in a variety of abusive actions toward them before they were 18 years old (e.g., slapping them, kicking them, or assaulting them with a knife or gun). Because of skew, the 16 individual items were first dichotomized $(0=$ never; $1=$ at least once) and then summed with a higher score indicating more types of physical abuse $(\alpha=.85)$. Approximately $95 \%$ experienced at least one form of physical abuse on at least one occasion.
Neglect comprised five items from a supplementary scale within the Parent-Child Conflict Tactics Scale, Form CTSPC-CA [35]. For example, respondents were asked how many times their caretaker left them at home alone when someone should have been with them. The items were first dichotomized because of skew and then summed such that a higher score indicated more types of neglect $(\alpha=.76)$. One form of neglect on at least one occasion was experienced by $78 \%$.

Sexual victimization comprised four items that focused on unwanted sexual experiences since they had been on their own. Items included having been touched sexually when they did not want to be and having been sexually assaulted and/or raped. Because of skew, each item was dichotomized and then summed such that a higher score indicated a greater number of different types of sexual victimization $(\alpha=.84)$.

Physical victimization was measured with six items that asked respondents, for example, how many times they had been beaten up or been robbed. A summed scale was created using these normally distributed items, with a higher score indicating more physical victimization $(\alpha=$ $.71)$.

Partner violence victimization included 13 items from the Revised Conflict Tactics Scale 2 to assess the amount of PV experienced by the youth [36]. Respondents were asked, for example, how many times their current or previous partner (e.g., boyfriend/girlfriend) did the following things to them: kicked, shoved, and choked. These 13 individual items were dichotomized ( $0=$ never; $1=$ at least once) and then collapsed because of skew. The final summed scale ranged from 0 to $6(\alpha=.89)$.

\section{Dependent variable}

$H I V$ risk behavior was measured using six items; five items pertained to sexual behaviors and one was on risky substance use. Respondents were asked with how many different people they had voluntary sexual intercourse (vaginal or anal) within the past 12 months $(0=0-2$ partners; $1=3$ partners or more); whether they have ever had an STD $(0=$ no; $1=$ yes $)$; age at first voluntary sexual intercourse ( $0=14$ or older; $1=13$ or younger); whether they had used a condom the last item they had voluntary sexual intercourse $(0=$ yes; $1=$ no); and whether they had ever traded sex or engaged in prostitution $(0=$ no; 1 = yes). For risky substance use behaviors, respondents were asked whether they had ever injected drugs $(0=$ no; $1=$ yes $)$. Because of the dichotomous nature of these coded variables and to ensure there were no missing cases on the dependent variable, a count scale was created in which a higher score indicated engaging in a greater number of HIV risk behaviors (range 0-4). Approximately $83 \%$ engaged in at least one HIV risk behavior on at least one occasion. Less than $2 \%$ of respondents were missing on any individual item. The sample characteristics are provided in Table 1. 


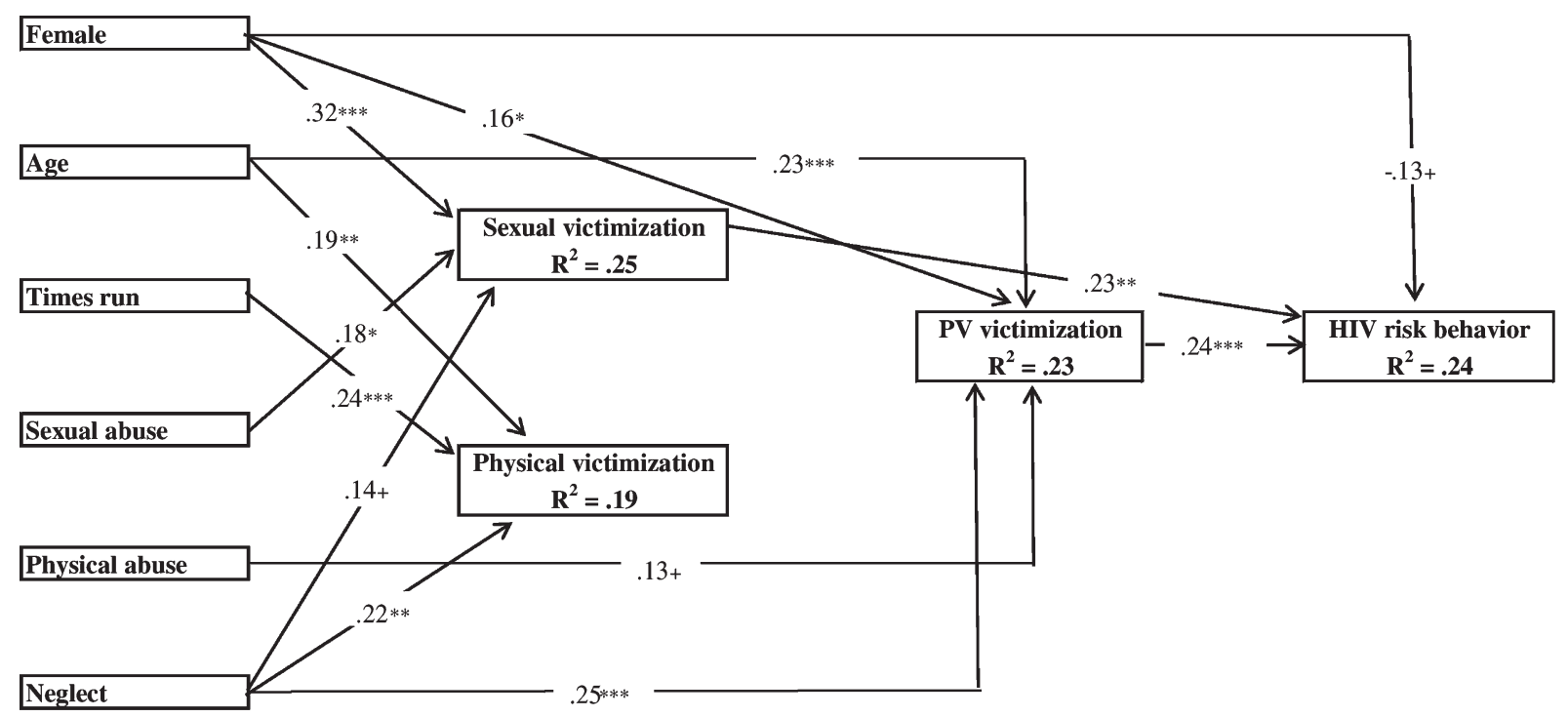

Figure 1. Path model for correlates of HIV risk behaviors ( $\mathrm{n}=172$, only significant paths shown). ${ }^{* *} p \leq .001,{ }^{* *} p \leq .01,{ }^{*} p \leq .05,+p \leq$ .10. $\mathrm{PV}=$ partner violence.

\section{Results}

To explore the effects of child maltreatment on HIV risk behaviors, we estimated a fully recursive path model using the weighted least squares procedure in Mplus 5.1 [37]. This model takes into account both the direct effects of child maltreatment on HIV risk behaviors as well as their indirect effects through sexual and physical victimization and partner violence victimization (Figure 1).

The results in Figure 1 (standardized coefficients shown) reveal that sexual abuse was associated with sexual victimization $(\beta=.18)$; young adults who had experienced sexual abuse were more likely to experience more forms of sexual victimization since being on the street. Having experienced more types of child physical abuse was positively related to being a victim of partner violence $(\beta=.13)$. Homeless young adults who experienced more types of neglect as a child were likely to report a greater number of different types of sexual victimization $(\beta=.14)$, physical victimization $(\beta=.22)$, and partner violence victimization $(\beta=.25)$. In terms of our mediators, those who experienced more types of sexual victimization on the street were likely to participate in a greater number of HIV risk behaviors ( $\beta$ $=.23$ ). Additionally, young people who experienced more partner violence victimization were likely to report engaging in a greater number of HIV risk behaviors $(\beta=.24)$. Regarding our control variables, youth who ran away from home more frequently and older respondents were more likely to experience more types of physical victimization since being on the street $(\beta=.24$ and $\beta=.19$, respectively). Older respondents were also more likely to experience more forms of partner violence $(\beta=.23)$. Finally, females were more likely to have been sexually victimized since being on the street $(\beta=.32)$ and experience more types of partner violence $(\beta=.16)$, whereas males were likely to engage in more types of HIV risk behaviors $(\beta=-.13)$. Our model explained $24 \%$ of the variance in HIV risk behaviors.
Table 1. Sample characteristics

\begin{tabular}{lcc}
\hline Dichotomous variables & $\mathrm{N}$ & $\%$ \\
\hline Gender & & \\
Female & 69 & 40.1 \\
Male & 103 & 59.9 \\
Sexual abuse & & \\
Yes & 80 & 47.1 \\
No & 90 & 52.9 \\
\hline Continuous variables & Mean & SD \\
\hline Age & 21.45 & 2.13 \\
Number of times run & 2.25 & 1.55 \\
Physical abuse & 5.98 & 3.55 \\
Neglect & 2.16 & 1.72 \\
Sexual victimization & .88 & 1.34 \\
Physical victimization & 5.78 & 4.02 \\
Partner violence victimization & 2.28 & 2.26 \\
HIV risk behavior & 1.68 & 1.23 \\
\hline
\end{tabular}

\section{Indirect effects}

Table 2, which shows the direct, indirect, and total effects for the full model on HIV risk behaviors, revealed that gender had a significant indirect effect on HIV risk behavior through sexual victimization and partner violence victimization. That is, females who experienced more forms of partner violence and sexual victimization were likely to engage in a greater number of different HIV risk behaviors. Age also had a significant indirect effect: older youth were more likely to experience more forms of partner violence which, in turn, led to greater participation in different HIV risk behaviors. Sexual abuse was also indirectly linked to HIV risk behaviors through sexual victimization. Finally, neglect and physical abuse were indirectly associated with HIV risk behaviors through partner violence. 
Table 2. Full model results (standardized)

\begin{tabular}{|c|c|c|c|c|c|c|}
\hline Variables & $\begin{array}{c}\text { Direct effect } \\
\text { estimate }\end{array}$ & SE & $\begin{array}{l}\text { Total indirect } \\
\text { effect estimate }\end{array}$ & SE & $\begin{array}{c}\text { Total effect } \\
\text { estimate }\end{array}$ & SE \\
\hline \multicolumn{7}{|l|}{ Demographic controls } \\
\hline Age & .086 & .072 & $.091^{* *}$ & .032 & $.177^{* * *}$ & .071 \\
\hline Times run & .113 & .072 & .036 & .031 & $.149^{* * *}$ & .073 \\
\hline Physical abuse & .011 & .077 & $.060^{* * *}$ & .029 & .071 & .080 \\
\hline Neglect & .028 & .082 & $.106^{* *}$ & .037 & $.135^{*}$ & .081 \\
\hline \multicolumn{7}{|l|}{ Mediating constructs } \\
\hline Sexual victimization & $.232^{* *}$ & .079 & -.009 & .019 & $.223^{* *}$ & .081 \\
\hline Physical victimization & .068 & .078 & -.004 & .019 & .064 & .080 \\
\hline
\end{tabular}

${ }^{*} p \leq .10$

${ }^{* *} p \leq .01$

${ }^{* * *} p \leq .05$

**** $p \leq .001$

a $\mathrm{PV}=$ partner violence.

\section{Discussion}

The purpose of the current study was to examine the relationship between child maltreatment, physical and sexual victimization, partner violence victimization, and HIV risk behaviors among a sample of homeless young adults. There is little research on the role that partner violence victimization plays among homeless young adults and it is important to assess whether it is an additional risk factor for HIV behaviors. Homeless youth and young adults are at higher risk for contracting HIV as a result of their lifestyles and participation in high risk behaviors. Failure to identify various forms of victimization among this population, including partner violence, may result in inadequate treatment and continued exposure, which may have long-term effects, including psychological distress and substance abuse [38, 39].

Consistent with previous research, we found direct effects between sexual victimization [8] and partner violence victimization [24-26] and HIV risk behaviors such as trading sex and injecting drugs. Experiencing more types of partner violence and/or sexual victimization was associated with engaging in a greater number of different HIV risk behaviors. We also found an association between child maltreatment and HIV risk behaviors, which is consistent with previous studies [7, 8, 12]. Specifically, we found several indirect relationships between child abuse and neglect through other forms of victimization. Sexual abuse and neglect were associated with sexual victimization which was, in turn, associated with HIV risk behaviors. Similarly, experiencing more types of physical abuse and/or neglect was indirectly associated with engaging in a greater number of HIV risk behaviors through partner violence. Our findings are consistent with our hypotheses and the riskamplification model.
According to the risk-amplification model [33], those who experience child maltreatment are at higher risk for running away so as to escape a negative home environment. These detrimental childhood experiences place homeless youth on early developmental trajectories that are amplified by the stressors they encounter on the street. As such, the cumulative effect of a noxious home environment and street life increases homeless youths' risk for experiencing physical and/or sexual victimization on the streets perpetrated by their partners and/or other known and unknown offenders. Violence in general has been associated with premature role exits and, consequently, exposure to aggression may influence a victim's early transition to adulthood [40], possibly without the skills necessary to effectively cope in the aftermath of a traumatizing situation. As such, victims of violence may lack the interpersonal skills necessary to negotiate safe sex practices and may engage in sexual behaviors that put them at risk for acquiring HIV. Similarly, homeless young adults may also participate in substance use behaviors, such as injection drug use, as a way to cope with these traumatizing events, increasing their risk for HIV infection. Overall, stressful life events originating in the family continue to affect youth after they leave home. Their ongoing victimization experiences over the life course may lead to participation in sexual and/or drug use behaviors that may ultimately lead to HIV infection.

There are some limitations to our study. All data are based on self-reports. Despite this, participants were informed that their responses would be confidential and the interviewers were already known and trusted by many of the young people so it is less likely that the respondents would be motivated to bias their responses. Some of the measures, such as child maltreatment, were retrospective, which may have resulted in some over- or underreporting. 
Finally, this study was cross-sectional; therefore, we cannot make inferences about causality.

Despite these limitations, our study has several strengths. We used path analyses to examine both the direct and indirect effects of childhood maltreatment and street victimization experiences on HIV risk behaviors instead of only examining direct associations. Using this method allowed us to understand more about the pathways from early victimization experiences to current health risk behaviors. Additionally, little research exists on partner violence among homeless youth. Although previous studies on homeless young adults have found that child abuse and victimization in general are associated with HIV risk behaviors [7, 8, 12], it was unknown whether partner violence victimization was a unique and additional risk factor among homeless youth, which our study addresses. We were also able to examine the effects of various forms of victimization on HIV risk behaviors, thus leading to a better understanding of how the circumstances of homeless young people may place them at risk for HIV infection.

The findings of our study have important implications for service providers. Clinicians who serve homeless youth should recognize the negative implications of experiencing a variety of forms of victimization to not only stop the cycle of violence but also prevent homeless young adults from participating in risky sexual and drug use behaviors. As such, our study provides further evidence that experiencing violence at the hands of loved ones, such as parents and intimate partners, may affect victims' health risk behaviors and clinicians should help homeless youth find effective ways to cope with their victimization experiences. Because of the link between victimization and HIV risk behaviors, health care providers may want to test partner violence victims for HIV and other STIs. It is also important to increase awareness of how unsafe sexual activities and substance use behaviors can place homeless youth at risk for contracting HIV. Increasing access and referrals to street health clinics are important intervention approaches.

\section{Acknowledgments}

This research was supported by the National Institute of Mental Health, grant number K01MH064897, Dr. Kimberly A. Tyler, PI.

\section{References}

[1] Centers for Disease Control and Prevention. Estimates of new HIV infections in the United States. Online at: http://0-www.cdc.gov.library.unl.edu/hiv/topics/surveillance/resources/factsheets/incidence.htm Accessed October 24, 2009.

[2] Office of National AIDS Policy. Youth and HIV/AIDS 2000: A new American agenda. Online at: http://www.thebody.com/content/art38.html Accessed October 24, 2009.
[3] D. M. Allen, S. Lehman, T. A. Green, et al., HIV infection among homeless adults and runaway youth, United States, 1989-1992, AIDS 8 (1994), pp. 1593-1598.

[4] American Public Human Services Association, Adolescents Served by Child Welfare Agencies: The Risk of HIV, STDs, and Unintended Pregnancies, American Public Human Services Association, Washington, DC (1999).

[5] J. A. Farrow , R. W. Deisher, R. Brown, et al., Health and health needs of homeless and runaway youth: A position paper of the society for adolescent medicine, 1992. Online at: http:/ / www.adolescenthealth.org/html/homeless.html Accessed March 3, 2004.

[6] R. W. Pfeifer and J. Oliver, A study of HIV seroprevalence in a group of homeless youth in Hollywood, California, $J$ Adolesc Health 20 (1997), pp. 339-342.

[7] T. P. Johnson, J. R. Aschkenasy, M.R. Herbers, et al., Self-reported risk factors for AIDS among homeless youth, AIDS Educ Prev 8 (1996), pp. 308-322.

[8] D. A. MacKellar, L. A. Valleroy, J. P. Hoffmann, et al., Gender differences in sexual behaviors and factors associated with nonuse of condoms among homeless and runaway youths, AIDS Educ Prev 12 (2000), pp. 477-491.

[9] K. A. Tyler, L. B. Whitbeck, D. R. Hoyt, et al., Predictors of self-reported sexually transmitted diseases among homeless and runaway adolescents, J Sex Res 37 (2000), pp. 369-377.

[10] B. M. Beech, L. Myers, and D. J. Beech, Hepatitis B and C infections among homeless adolescents, Fam Community Health 25 (2002), pp. 28-36.

[11] L. L. Halcon and A. R. Lifson, Prevalence and predictors of sexual risks among homeless youth, J Youth Adolesc 33 (2004), pp. 71-80.

[12] K. A. Tyler, Risk factors for trading sex among homeless young adults, Arch Sex Behav 38 (2009), pp. 290-297.

[13] M. . Rotheram-Borus, H. Meyer-Bahlburg, and C. Koopman et al., Lifetime sexual behaviors among runaway males and females, J Sex Res 29 (1992), pp. 15-29.

[14] J. E. Anderson, T. E. Freese, and J. N. Pennbridge, Sexual risk behavior and condom use among street youth in Hollywood, Fam Plann Perspect 26 (1994), pp. 22-25.

[15] E. Goodman and J. E. Berecochea, Predictors of HIV testing among runaway and homeless adolescents, J Adolesc Health 15 (1994), pp. 566-572.

[16] L. S. Wagner, L. Carlin, A.M. Cauce, et al., A snapshot of homeless youth in Seattle: Their characteristics, behaviors and beliefs about HIV protective strategies, J Community Health 26 (2001), pp. 219-232.

[17] M. J. Rotheram-Borus and C. Koopman, Sexual risk behaviors, AIDS knowledge, and beliefs about AIDS among runaways, Am J Public Health 81 (1991), pp. 208-210.

[18] S. L. Bailey, C. S. Camlin, and S. T. Ennett, Substance use and risky sexual behavior among homeless and runaway youth, J Adolesc Health 23 (1998), pp. 378-388.

[19] J. M. Greene, S. T. Ennett, and C. L. Ringwalt, Substance use among runaway and homeless youth in three national samples, Am J Public Health 87 (1997), pp. 229-235. 
[20] M. D. Kipke, J. B. Unger, R.F. Palmer, et al., Association between self identified peer-group affiliation and HIV risk behaviors among street youth. In: J.B. Greenberg and M.S. Neumann, Editors, What we have learned from the AIDS Evaluation of Street Outreach Projects, Centers for Disease Control, Atlanta, GA (1998), pp. 61-82.

[21] P. S. Plass and G. T. Hotaling, The intergenerational transmission of running away: Childhood experiences of the parents of runaways, J Youth Adolesc 24 (1995), pp. 335-348.

[22] K. A. Tyler, D. R. Hoyt, and L. B. Whitbeck et al., The impact of childhood sexual abuse on later sexual victimization among runaway youth, J Res Adolesc 11 (2001), pp. 151-176.

[23] S. T. Ennett, E. B. Federman, and S. L. Bailey et al., HIVrisk behaviors associated with homelessness characteristics in youth, J Adolesc Health 25 (1999), pp. 344-353.

[24] M. R. Decker, J. G. Silverman, and A. Raj, Dating violence and sexually transmitted disease/HIV testing and diagnosis among adolescent females, Pediatrics 116 (2005), pp. e272-e276.

[25] A. J. Heintz and R. M. Melendez, Intimate partner violence and HIV/STD risk among lesbian, gay, bisexual, and transgender individuals, J Interpers Violence 21 (2006), pp. 193-208.

[26] B. W. Weir, R. S. Bard, K. O'Brien, et al., Violence against women with HIV risk and recent criminal justice system involvement: Prevalence, correlates, and recommendations for intervention, Violence Against Women 14 (2008), pp. 944-960.

[27] A. M. Teitelman, S. J. Ratcliffe, M. M. Morales-Aleman, et al., Sexual relationship power, intimate partner violence, and condom use among minority urban girls, J Interpers Violence 23 (2008), pp. 1694-1712.

[28] S. Maman, J. Campbell, M.D. Sweat, et al., The intersections of HIV and violence: Directions for future research and interventions, Soc Sci Med 50 (2000), pp. 459-478.

[29] E. Wu, N. El-Bassel, S. S. Witte, et al., Intimate partner violence and HIV risk among urban minority women in primary health care settings, AIDS Behav 7 (2003), pp. 291-301.
[30] C. S. North, S. J. Thompson, and E. M. Smith et al., Violence in the lives of homeless mothers in a substance abuse treatment program: A descriptive study, J Interpers Violence 11 (1996), pp. 234-249.

[31] C. S. North, E. M. Smith, and E. L. Spitznagel, Violence and the homeless: An epidemiologic study of victimization and aggression, J Trauma Stress 7 (1994), pp. 95-110.

[32] K. A. Tyler, L. A. Melander, and H. Noel, Bidirectional partner violence among homeless young adults: Risk factors and outcomes, J Interpers Violence 24 (2009), pp. 1014-1035.

[33] L. B. Whitbeck, D. R. Hoyt, and K. A. Yoder, A risk-amplification model of victimization and depressive symptoms among runaway and homeless adolescents, Am J Community Psychol 27 (1999), pp. 273-296.

[34] J. D. Wright, T. L. Allen, and J. A. Devine, Tracking nontraditional populations in longitudinal studies, Eval Program Plann 18 (1995), pp. 267-277.

[35] M. A. Straus, S. L. Hamby, and D. Finkelhor et al., Identification of child maltreatment with the Parent-Child Conflict Tactics Scales: Development and psycho-metric data for a national sample of American parents, Child Abuse Negl 22 (1998), pp. 249-270.

[36] M. A. Straus, S. L. Hamby, and S. Boney-McCoy et al., The Revised Conflict Tactics Scales (CTS2): Developmental and preliminary psychometric data, J Fam Issues 17 (1996), pp. 283-316.

[37] L. K. Muthén and B. O. Muthén, Mplus User's Guide (5th ed.), Muthén and Muthén, Los Angeles, CA (1998-2007).

[38] A. Salomon, S. S. Bassuk, and N. Huntington, The relationship between intimate partner violence and the use of addictive substances in poor and homeless single mothers, Violence Against Women 8 (2002), pp. 785-815.

[39] M. Schiff, N. El-Bassel, and M. Engstrom et al., Psychological distress and intimate physical and sexual abuse among women in methadone maintenance treatment programs, Soc Serv Rev 76 (2002), pp. 302-320.

[40] J. Hagan and H. Foster, Youth violence and the end of adolescence, Am Sociol Rev 66 (2001), pp. 874-899. 